\title{
Achievable Altitudes for Hydrogen Fueled Fuel Cell Powered Unmanned Air Vehicles
}

\author{
Nevzet Kaya
}

\begin{abstract}
Maximum achievable altitudes of hydrogen fueled, air fed fuel cell stack powered unmanned air vehicles were investigated. Necessary thrust was considered to be provided by some ducted fan system(s), as many as required, each including a fan, a fuel cell stack (FCS) air-fed by a centrifugal compressor, two electric motors for driving the fan and the compressor and an inverter for converting d.c. electrical output of the FCS to a.c. All the remnant heat of fuel reaction and heat generated in the powertrain was considered to be transferred to the air flow inside the duct. Hydrogen storage capacity was assumed to be $7 \%$ and maximum fuel use for climb were limited to $50 \%$ of fuel onboard. Fuel stack power to weight ratio and operating temperature were assumed to be $1 \mathrm{~kW} / \mathrm{kg}$ and $100^{\circ} \mathrm{C}$ respectively. Results include maximum achievable altitudes with respect to some paired combinations of input variables such as thrust to weight ratio, drag to weight ratio and stall speed of the UAV and the fan's polytrophic efficiency. Results indicate that, $1 \mathrm{~kW} / \mathrm{kg}$ power densities of FCS are not sufficient to bring the UAVs over $8 \mathrm{~km}$ altitude mainly due to operation of the system elements, such as fuel cell stack, electric motor and inverter, at off-design points.
\end{abstract}

Index Terms - Ducted Fan, Fuel cell, Hydrogen, Unmanned air vehicle.

\section{INTRODUCTION}

Unmanned air vehicles (UAVs) have many advantages arising mainly from their freedom to carry a human pilot. This freedom provides the UAV designers a design flexibility to extend their design limits and chose the best options for a mission without being obliged to consider requirements or capabilities of a human pilot onboard. A wide variety of UAVs, in terms of type, size, mission, etc. are already in use, many others being under development in a number of countries by many manufacturers and much more are in the focus of research efforts all over the world [1-5]. Intensive UAV operations in civilian airspaces are retarded by regulatory issues yet, mainly due to security concerns [6]. High altitude long endurance (HALE) UAVs have the advantage of overcoming this barrier by operating at altitudes above civilian airspaces. There are many regarding HALE UAVs as a viable option for missions such as surveillance, monitoring, communication and data transfer, even as a candidate for replacing geosynchronous (GEO) and low-earth-orbit (LEO) satellites due to their advantages such as higher effectiveness, lower initial and maintenance costs, simpler launch and being recoverable/reusable [7-8].

Maximum achievable altitude is a key performance parameter for a UAV determining its suitability for a mission, if it is not brought to its mission altitude by some external means.

Nevzet Kaya, Anadolu University, Faculty of Aeronautics and Astronautics, 26470, Eskişehir, Turkey
Climb performances, hence the maximum achievable altitude, of a UAV is determined by its power requirement, energy or power conversion efficiency and available energy source. The main power requirement of an air vehicle is for its propulsion either for bringing it to its mission altitude or for keeping it aloft. On the other hand, the propulsion requirement is directly related to the total weight of the air vehicle. Energy/power conversion may cover a variety of types including chemical to heat, mechanical or electrical, heat to mechanical, mechanical to propulsion, etc. Available energy sources may be in the form of fuel onboard or external energy sources such as the Sun or geopotential energy.

Fuel cells (FC) are in the focus of researches and studies as one of the most popular power generation system for the near future due to their numerous advantages such as high power efficiencies with respect to heat engines, high design flexibility presenting almost no restriction for size, geometry or power, besides, having a broad range of fuel choice, including environment friendly ones such as hydrogen. Nevertheless, current power densities of FCs, below $1 \mathrm{~kW} / \mathrm{kg}$, does not allow their applicability on a broad range of air vehicle types, where weight is a critical concern.

In above mentioned respects, maximum achievable altitudes of UAV powered with hydrogen fueled fuel cell stacks (FCS) are investigated in this study. The key parameters determining the maximum climb altitudes and flight time of an air vehicle are its weight, thrust to weight ratio, drag to weight ratio, stall speed and efficiency of its propulsive system. Therefore, these parameters were taken as the input variables in this study. A ducted fan propulsion system was preferred both due to its suitability for high altitude operations and its advantage providing to make maximum use of the remnant heat of FCS. Maximum fuel use was restricted to $50 \%$ of the fuel onboard, in order to allow some fuel use for mission requirements in the cruise phase.

\section{Methodology}

\section{A. General Assumptions}

The UAVs were assumed to have a number of power and propulsion system, as many as required, main elements and sections of which are shown on Fig. 1. Each fan (F) is assumed to be driven by an electric motor (EM) powered by a fuel cell stack (FCS), all taking place in the same duct. DC output of the FCS is converted to AC by an inverter (Inv) before applied to the EM. All the air flow through the fan duct and FCS were assumed to be completely mixed in the mixer (Mix) before the exit section. All the climbs were considered to be taking place in the US Standard Atmosphere 1976 and all the gasses are assumed to be ideal. 


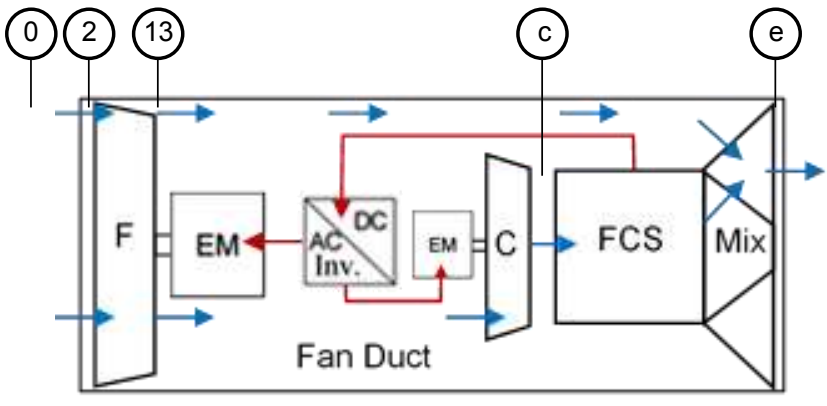

Fig. 1. UAV's power and propulsion system schematic

Efficiency variations of all the elements of the power and propulsion system with their power delivery and environmental conditions are taken into account. Pressure loses all along the fan duct, including those occurring in the FCS, are taken into account by a combined Fan\&Duct polytropic efficiency. The Mach number of the gas flow at the exit of the fan duct at take-off was restricted to 0.72 , in order not to have some supersonic, hence choked, flows at high altitudes. The fan's tip mach number was restricted to 1 and assumed to be constant at all altitudes. Efficiency variation of the EM and the inverter with power use or delivery were assumed to be as shown Fig.2, which are quite close to relevant figures given in [9] and [10] respectively.

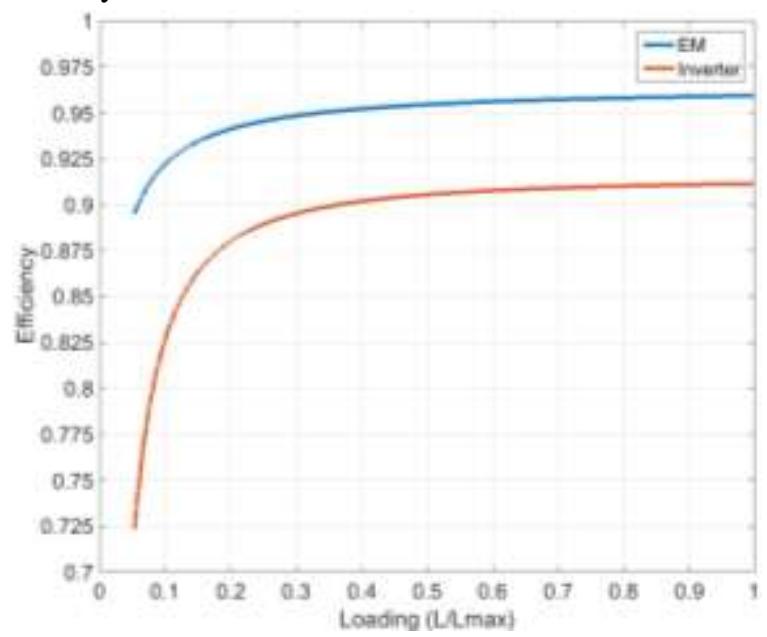

Fig.2. EM and inverter efficiency variation with loading

Fuel is assumed to be entering the FCS as pure hydrogen at environment temperature. As higher operating temperatures yields lower Gibbs free energies, hence lower FCS electrical efficiencies, the FCS was assumed to be operating at a low temperature, but still close to the practical applications such as $100^{\circ} \mathrm{C}$, in order to be able to see some best but realistic results. Mass transport losses in the FCS are ignored as the pressure through it will be around 1.4 bar at take-off and will decrease even more with altitude. Total ohmic loses including that of the FCS, the EM and the inverter were assumed to be $2 \%$. Some other operational constants together with the variable input parameters are given in Table 1.
TABLE 1. RANGES OF INPUT PARAMETERS AND SOME CONSTANTS

\begin{tabular}{|c|c|c|c|}
\hline Variable Input Parameter & Min. & Max. & \\
\hline \multicolumn{2}{|c|}{ Drag to Weight Ratio (DWR) } & 0.02 & 0.05 \\
\hline \multicolumn{2}{|c|}{ Thrust to Weight Ratio at Take-Off $\left(T W R_{00}\right)$} & 0.1 & 0.4 \\
\hline \multicolumn{2}{|c|}{ Fan\&Duct Combined Polytropic Efficiency $\left(\eta_{F \& D}\right)$} & 0.5 & 1 \\
\hline \multicolumn{2}{|c|}{ Stall Speed at Take-Off $\left(v_{00}\right)$} & $10 \mathrm{~m} / \mathrm{s}$ & $50 \mathrm{~m} / \mathrm{s}$ \\
\hline \multicolumn{4}{|c|}{ Constants } \\
\hline \multicolumn{4}{|c|}{ Duct Exit Mach Number at TO $\left(M_{e, 00}\right)=0.72$} \\
\hline \multicolumn{4}{|c|}{ Centrifugal Compressor Pressure Ratio $\left(\pi_{C}\right)=3$} \\
\hline \multicolumn{4}{|c|}{ Fuel Cell Power Density $=0.5 \mathrm{~W} / \mathrm{cm}^{2}$} \\
\hline \multicolumn{4}{|c|}{ Fuel System Weight to UAV Weight Ratio at TO $=0.50$} \\
\hline \multicolumn{4}{|c|}{ Hydrogen Storage Capacity by Mass $=7 \%$} \\
\hline \multicolumn{4}{|c|}{ FCS Power Density $=1 \mathrm{~kW} / \mathrm{kg}$} \\
\hline \multicolumn{4}{|c|}{$W_{F C S} / T O W=0.25$} \\
\hline
\end{tabular}

\section{B. Conceptual Design of the Power and Propulsion System}

As all of the input parameters, as well as the key constants have intensive characteristic, it doesn't matter what the actual weight of the UAV is for calculating its flight characteristics. Therefore, the TOW of the UAV was arbitrarily taken as 1000 $\mathrm{kg}$. Power and propulsion system of the UAV was determined according to its thrust to weight ratio at take-off conditions. Table 2 gives the calculation steps for the conceptual design of the power and propulsion system.

TABLE 2. CALCULATION STEPS FOR CONCEPTUAL DESIGN OF THE POWER AND PROPULSION SYSTEM

\begin{tabular}{|c|c|c|}
\hline \multicolumn{2}{|c|}{ Input Parameters } & \multirow[b]{2}{*}{ Output parameters } \\
\hline \begin{tabular}{|c|} 
Taken or calculated \\
from the initial values
\end{tabular} & $\begin{array}{l}\text { Calculated in the previous } \\
\text { steps }\end{array}$ & \\
\hline$T O W, T W R_{U A V}$ & & $F_{00}$ \\
\hline $\begin{array}{c}T_{00}, P_{00} \\
v_{00}, M_{e, 00}, \pi_{C}\end{array}$ & & $\begin{array}{c}T_{2, t, 00}, \pi_{F, 00}, T_{13, t, 00} \\
T_{c, t, 00}, T_{e, t, 00}, v_{e, 00} \\
P_{c, t, 00}, P_{e, t, 00} \\
P_{H 2,00}, P_{O 2,00}, P_{H 2 O, 00}\end{array}$ \\
\hline $\begin{array}{c}T_{f c}, I_{0, f c}, P_{00} \\
\eta_{E M, 00}, \eta_{i n v, 00}\end{array}$ & $P_{H 2,00}, P_{O 2,00}, P_{H 2 O, 00}$ & $\begin{array}{c}V_{f c, 00}, i_{f c, 00}, \eta_{f c, 00} \\
\eta_{o v l, 00,}, \dot{m}_{f, 00}\end{array}$ \\
\hline $\begin{array}{c}M_{e, 00}, M_{00}, T_{00} \\
\eta_{F \& D}\end{array}$ & $\begin{array}{c}\frac{P_{13, t, 00}}{P_{00}}, \frac{T_{13, t, 00}}{T_{00}}, \\
\eta_{o v l, 00}\end{array}$ & $\frac{T_{e, s, 00}}{T_{00}}$ \\
\hline$M_{00}, M_{e, 00}, v_{00}$ & $\frac{T_{e, s, 00}}{T_{00}}, F_{00}$ & $\dot{m}_{a, 00}$ \\
\hline$M_{00}, T_{00}$ & $\dot{m}_{a, 00}$ & $A_{F}$ \\
\hline$M_{00}, T_{00}, \eta_{F \& D}$ & $\frac{T_{13, t, 00}}{T_{00}}, \dot{m}_{a, 00}$ & $\dot{W}_{F, 00}$ \\
\hline & $\dot{W}_{F, 00}, \eta_{o v l, 00}$ & $\dot{W}_{F C S, 00}$ \\
\hline & $\dot{W}_{F C S, 00}, V_{f c, 00}, i_{f c, 00}$ & $N_{f c}, V_{F C S}$ \\
\hline
\end{tabular}

\section{In Flight Calculations}

Calculation steps used for take-off conditions were repeated to calculate the FCS performances with respect to actual conditions where necessary. The fan's spin rate was reduced with altitude, to keep a constant Mach number, according to,

$N 1(h)=N 1_{00} \cdot \sqrt{\frac{T_{0}(h)}{T_{00}}}$ 
Resulting air mass flow and fan pressure ratios were calculated accordingly. Minimum speed requirement for the $\mathrm{UAV}$, for a safe control, at an altitude $\mathrm{h}$ is,

$v_{0}(h)=v_{00} \cdot \sqrt{\frac{\rho_{00}}{\rho_{0}(h)}}$

Referring to Fig. 3 the force balance on an aircraft during climb is given by,

$F=D+W_{U A V} \cdot \sin (\beta)+\frac{a}{g} \cdot W_{U A V}$

Assuming linear accelerations between two adjacent segments of altitudes for calculation,

$a=\frac{v_{0}^{2}(h+d h)-v_{0}^{2}(h)}{2 \cdot d h} \cdot \sin (\beta)$

Therefore, the maximum climb angle can be calculated from,

$\sin (\beta)=\frac{\frac{F-D}{W_{U A V}}}{1+\frac{v_{0}^{2}(h+d h)-v_{0}^{2}(h)}{2 \cdot g \cdot d h}}=\frac{T W R-D W R}{1+\frac{v_{0}^{2}(h+d h)-v_{0}^{2}(h)}{2 \cdot g \cdot d h}}$

Calculations were ended either when the excess thrust (F-D) was not available or the maximum allowed fuel use was reached.

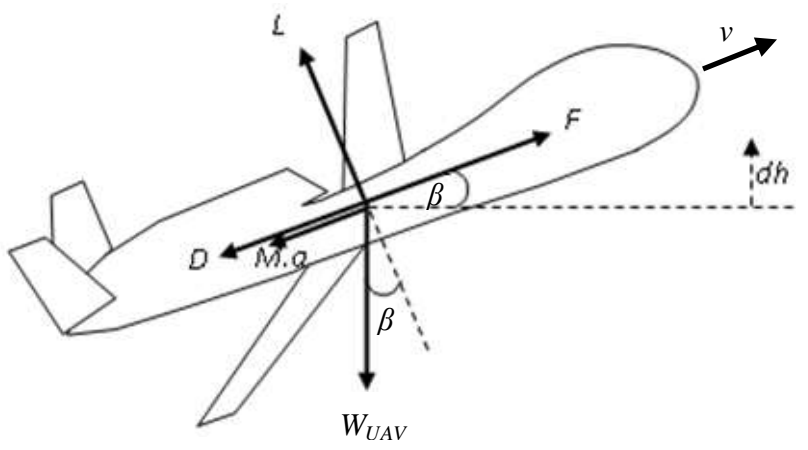

Fig. 3. Force balance on an air vehicle in climb

\section{RESULTS}

Loadings and efficiencies of the power and propulsion system elements in between $0-20 \mathrm{~km}$ altitudes are shown in Fig.4. Fan loading at $16 \mathrm{~km}$ altitude is almost $10 \%$ of its loading at sea level, hence all the power \& propulsion system elements, operate far away from their design points, resulting in significant efficiency drops, except for the EM, which indicates a slight decrease in efficiency. Actually, FC efficiency increases with decreasing loads, but decrease in its system/operating pressure does not allow it to make use of this advantage.

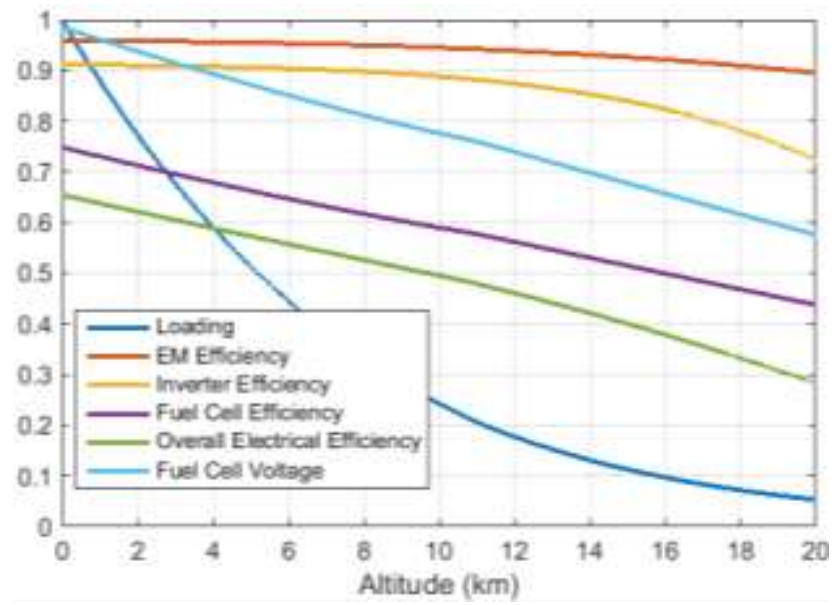

Fig.4. Loading and performances of power and propulsion system elements.

Maximum achievable altitudes with respect to some paired combinations of input parameters are shown in figures 5 to 9 . The variable input parameters, other than the inspected pair, are taken as the average of their range in general, if not stated otherwise.

\section{A. Maximum achievable altitudes with respect to varying TAchievable Altitudes with Varying TWR \& DWR}

Maximum achievable altitudes with respect to varying TWRs and DWRs are shown in Fig.5. Achievable altitudes increase with increasing TWRs and decreasing DWRs, which determine the amount of excess thrust. For stall speeds of $30 \mathrm{~m} / \mathrm{s}$ and higher, TWRs higher than about 0.1 requires some FCS power, hence FCS weight, exceeding 0.25 of TOW. Therefore, achievable altitudes were not calculated for these TWRs.

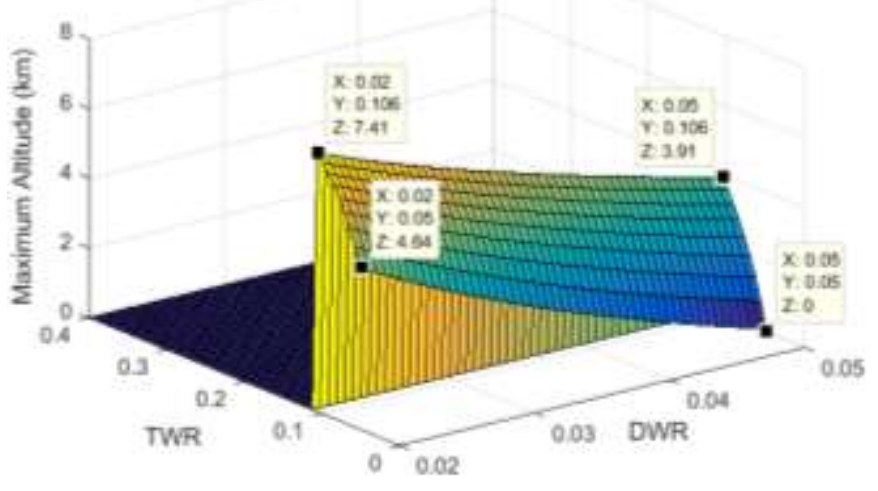

Fig. 5. Achievable altitudes with varying TWR \& DWR $\left(\mathrm{n}_{\mathrm{F} \& \mathrm{D}}=0.75\right.$, $\mathrm{v}_{00}=30 \mathrm{~m} / \mathrm{s}$ )

B. Achievable Altitudes with Varying TWR and Fan\&Duct Polytrophic Efficiencies

Maximum achievable altitudes with respect to varying TWR and fan\&duct polytrophic efficiencies are shown in Fig.6. Achievable altitudes increase with increasing TWRs and fan\&duct polytrophic efficiencies, as could be expected. Nevertheless, they are still away from being satisfactory for the selected DWR and stall speed (averages of their ranges respectively). Lower DWRs and stall speeds at sea level would yield higher achievable altitudes. 


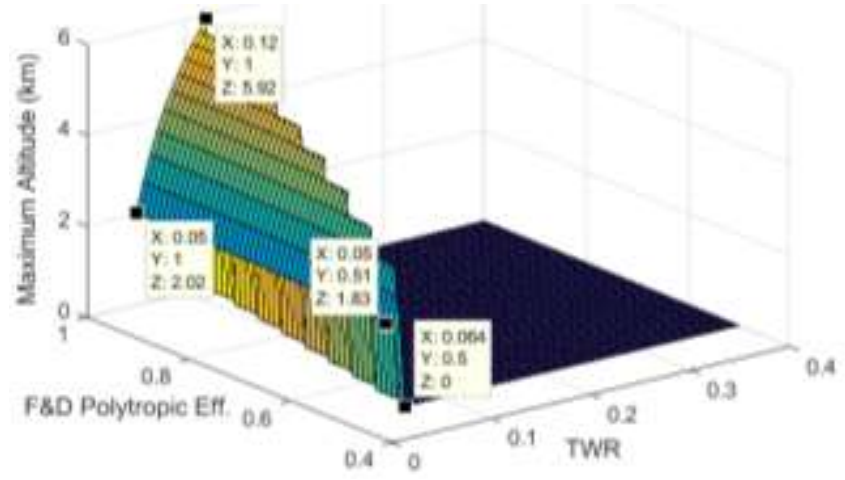

Fig. 6. Achievable altitudes with varying TWR and Fan\&Duct polytrophic efficiencies $\left(\mathrm{DWR}=0.035, \mathrm{v}_{00}=30 \mathrm{~m} / \mathrm{s}\right.$ )

\section{Achievable Altitudes with Varying TWR and Stall Speeds at Sea Level}

Maximum achievable altitudes with respect to varying TWR and stall speeds at seal level are shown in Fig.7. The fan\&duct polytrophic efficiency was taken as 0.90 in order not to underestimate some reasonable potentials.

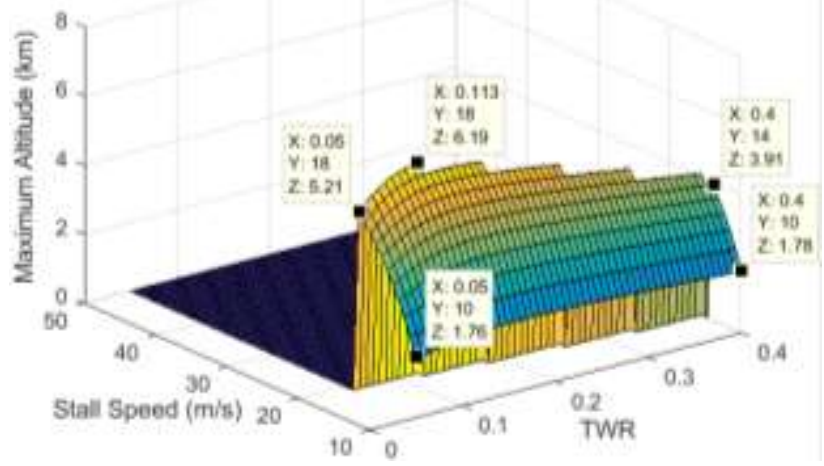

Fig. 7. Achievable altitudes with varying TWR and stall speeds at seal level $\left(\mathrm{DWR}=0.035, \mathrm{n}_{\mathrm{F} \& \mathrm{D}}=0.90\right)$

\section{Achievable Altitudes with Varying DWR and Stall Speeds at Sea Level}

Maximum achievable altitudes with respect to varying DWR and stall speeds at sea level are shown in Fig.8. TWR was taken as 0.1 as its higher values requires heavier FCS and don't allow to see the results for stall speeds over $25 \mathrm{~m} / \mathrm{s}$.

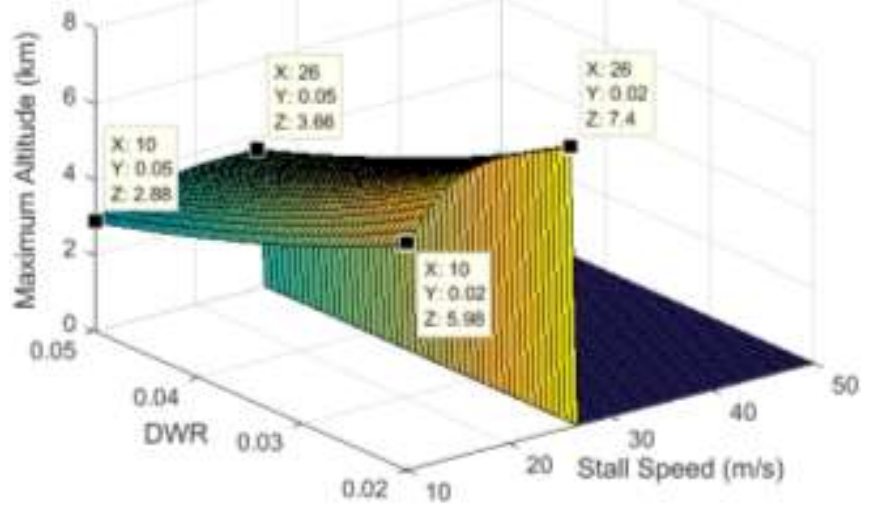

Fig. 8. Achievable altitudes with varying DWR and stall speeds at seal level $\left(\mathrm{TWR}=0.1, \mathrm{n}_{\mathrm{F} \& \mathrm{D}}=0.75\right)$

\section{E. Achievable Altitudes with Varying F\&D Polytrophic Efficiencies and Stall Speeds at Sea Level}

Maximum achievable altitudes with respect to varying F\&D polytrophic efficiencies and stall speeds at sea level are shown in Fig.9. Even TWR and DWR were taken as 0.1 and 0.025 respectively, to see the results for high stall speeds, the ranges of the feasible input/design parameters are quiet restricted.

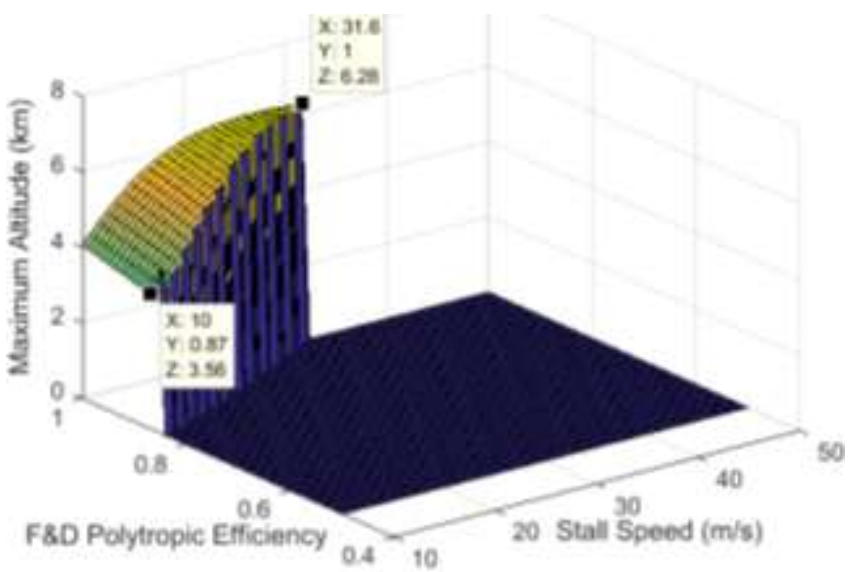

Fig. 9. Achievable altitudes with varying fan\&duct polytropic efficiencies and stall speeds at seal level $(\mathrm{TWR}=0.1, \mathrm{DWR}=0.025)$

\section{CONCLUSION}

Achievable altitudes of air vehicles are determined by available excess thrust and energy along its climb phase. Available excess thrust is determined by propulsion performance (namely TWR) and aerodynamic performance (namely DWR) of the air vehicle, while available energy is determined by specific energy (LHV or HHV) and storage capacity of the fuel.

Available thrusts and power of air-breathing systems, hence the power requirement, decrease with altitude due to decreasing air densities, resulting in off-design point operation of the power and propulsion system elements. Even, fuel cell efficiencies increase with decreasing power output, they decrease with altitude due to decreasing ambient pressure, hence their operating pressure, with altitude.

Main reason for fuel cell powered air vehicles being not able to achieve high altitudes is actually deficient fuel cell power densities, restricting excess thrust much at high altitudes. Besides, lower hydrogen storage capacities aggravate the situation. Even improving aerodynamic performances of the air vehicle, such as decreasing its drag and stall speed helps to improve the achievable altitudes, climbing to and cruising for a reasonable time at altitudes over $8-10 \mathrm{~km}$ with air-breathing hydrogen fueled fuel cells doesn't seem to be feasible with the current state of technology.

\section{Nomenclature}

Abbreviations

$\begin{array}{ll}\text { DWR } & : \text { Drag to Weight Ratio } \\ \text { EM } & : \text { Electric Motor } \\ \text { F } & : \text { Fan } \\ \text { GEO } & : \text { Geosynchronous } \\ \text { FC } & : \text { Fuel Cell } \\ \text { FCS } & : \text { Fuel Cell Stack } \\ \text { LEO } & : \text { Low Earth Orbit }\end{array}$




\section{LHV : Lower Heating Value \\ HALE : High Altitude Long Endurance \\ HHV : Higher Heating Value \\ TO : Take-Off \\ TOW : Take-Off Weight \\ TWR : Thrust to Weight Ratio \\ UAV : Unmanned Air Vehicle}

Symbols

a : Acceleration

$A_{a c} \quad$ : Activation overpotentail coefficient

D $\quad$ : Drag

F : Thrust, Force

g : Earth's gravitational acceleration

h : Altitude

M : Mach number, Molar mass

$\dot{m} \quad$ : Mass flow rate

$\mathrm{N} \quad$ : Number, mole number

N1 : : Fan spin rate

$\mathrm{P} \quad$ : Pressure

$\mathrm{T} \quad$ : Temperature

$\mathrm{v} \quad$ : Speed

W : Weight

$\dot{W} \quad$ : Work rate (power)

$X_{L} \quad:$ Load factor (Load/Maximum Load)

Subscripts

$00 \quad$ : At sea level standard conditions

$0 \quad$ : Ambient conditions or with respect to ambient

a : Air

c : Compressor

e : : Exit

EM : Electric motor

F : Fan

f : Fuel

fc : Fuel cell

FCS : Fuel cell stack

h : : Altitude

Inv : Inverter

ovl : Overall

r : Relative, reaction

S : Static

t : Total

Greek Letters

$\begin{array}{ll}\beta & : \text { Climb angle } \\ \eta & : \text { Efficiency } \\ \pi & : \text { Pressure ratio } \\ \rho & : \text { Density }\end{array}$

\section{REFERENCES}

[1] Air \& Space Europe, Current and future UAV military users and applications, Air \& Space Europe, Volume 1, Issues 5-6, SeptemberDecember 1999, Pages 51-58.

[2] USA DoD, Unmanned Aircraft Systems (UAS) Roadmap 2005-2030, http://fas.org:8080/irp/program/collect/uav_roadmap2005.pdf

[3] AIA, Unmanned Aircraft Systems: Perceptions \& Potentials, http://www.aia-aerospace.org/assets/AIA_UAS_Report_small.pdf

[4] Cox, T.H., Nagy, C.J., Skoog, M.A., and Somers, I.A., "Civil UAV Capability Assessment, Draft Version", prepared for UAV Vehicle Sector Manager, Vehicle Systems Program, NASA Aeronautics Mission Directorate,

https://www.nasa.gov/centers/dryden/pdf/111761main_UAV_Capabiliti es_Assessment.pdf

[5] Kapseong Ro, Jun-Seok Oh, and Liang Dong, Lessons Learned: Application of Small UAV for Urban Highway Traffic Monitoring, 45th AIAA Aerospace Sciences Meeting and Exhibit, 8 - 11 January 2007, Reno, Nevada.

[6] Dalamagkidis K., Valavanis K.P., Piegl L.A., (2008), On unmanned aircraft systems issues, challenges and operational restrictions preventing integration into the National Airspace System, Progress in Aerospace Sciences, Vol. 44, pp: 503-519.

https://doi.org/10.1016/j.paerosci.2008.08.001

[7] B. Gütlich, R. Meyer, S. Philipp-May, and A. Pagels-Kerp, "German Roadmap on Optical Communication in Space," in Advanced Solid-State Lasers Congress, P. McManamon, . Watson, and O. Steinvall, eds., OSA Technical Digest (online) (Optical Society of America, 2013), paper LM1B.2.

https://doi.org/10.1364//sc.2013.lm1b.2

[8] Visconti, G., P. Carlo, et al. (2007). Uninhabited Aerial Vehicles: Current and Future Use. Observing Systems for Atmospheric Composition, Springer New York: 106-118.

[9] Shyi-Min Lu, A review of high-efficiency motors: Specification, policy and technology, Renewable and Sustainable Energy Reviews, 2016, Vol 59:1-12. https://doi.org/10.1016/j.rser.2015.12.360

[10] G.A. Rampinelli, A. Krezinger, F. Chenle Romero, Mathematical models for efficiency of inverters used in grid connected photovoltaic systems, 2014, Vol.34: 578-587. 